\title{
KODAKCoin: a blockchain revolution or exploiting a potential cryptocurrency bubble?
}

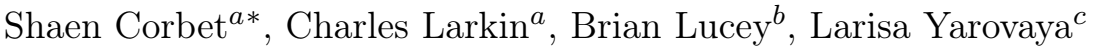 \\ ${ }^{a}$ DCU Business School, Dublin City University, Dublin 9 \\ ${ }^{b}$ Trinity Business School, Trinity College Dublin, Dublin 2 \\ ${ }^{c}$ Lord Ashcroft International Business School, Anglia Ruskin University, Chelmsford, UK \\ *Corresponding Author: shaen.corbet@dcu.ie
}

\begin{abstract}
Eastman Kodak is an American technology company that produces imaging products. In 2018, it announced its intentions to enter the crytpocurrency market, raising concerns that it could be taking advantage of a potential cryptocurrency bubble for short-term gains. We analyse the relationships between Kodak, crytocurrency and stock market index returns. We find evidence of a significant, sustained increase in both the share price and price volatility of Kodak after the KODAKCoin announcement, with an increased correlation between the price of Kodak shares and Bitcoin.
\end{abstract}

Keywords: Cryptocurrencies; Digital Assets; GARCH; Kodak; KODAKCoin. 


\section{Introduction}

In January 2018, camera manufacturer Eastman Kodak announced that it was entering the cryptocurrency market through the creation of KODAKOne, described as a revolutionary new image rights management and protection platform secured in the blockchain. At $5.00 \mathrm{pm}$ (GMT) on 9 January, Kodak shares were worth $\$ 3.10$. At $2.40 \mathrm{pm}$ (GMT) on 10 January, shares were trading at $\$ 12.75$. Kodak, a company who had witnessed in excess of a $90 \%$ fall in their share price between 2014 and 2018 became the centre of attention, central to which was a simple question: 1) had Kodak just unveiled a novel and genius evolutionary use for blockchain; or 2) had Kodak just attempted to ride the wave of a potential cryptocurrency bubble?

This paper builds on those that investigate the price and volatility of cryptocurrencies. Kodak's use of a cryptocurrency to exploit market sentiment and price growth should be related to volatility dynamics and correlations between the cryptocurrency and equity products, if those align, even in the short-term, following the announcement. The primary fear about cryptocurrencies is the existence of a pricing bubble (Corbet et al. [2017]). Recently, the focus of research has expanded from the technical aspects of cryptocurrency markets (Dwyer [2015]), to that of the effects of speculation (Blau [2017]), market efficiency (Urquhart [2016]) and the potential diversification effects associated with cryptocurrencies (Corbet et al. [2018]).

We contribute by addressing two key questions. First, using a $\operatorname{GARCH}(1,1)$ methodology we provide empirical evidence on the changing price volatility in the aftermath of the KODAKCoin announcement. Secondly, using a DCC-GARCH methodology we analyse the changing dynamic correlations between both Kodak and the Dow Jones Industrial Average (DJIA, as a measure of stock returns), and Kodak and Bitcoin (as a measure of cryptocurrency returns). We show that along with a significant increase in share price volatility, the relationship between Kodak and the broad stock market began to break down in the aftermath of the announcement, however, of regulatory and policy-making interest, the relationship between Kodak and Bitcoin strengthened significantly.

Our paper is organised as follows. Section 2 discussed the potential rationale behind the evolution of KODAKCoin and why interlinkages between publicly traded companies and cryptocurrencies could be potentially hazardous. Section 3 presents our data and some preliminary statistics. Section 4 discusses the empirical frameworks and the findings. Section 5 concludes the paper.

\section{The evolution of KODAKCoin}

On the 9 January 2018, Kodak announced that it intended entering the cryptocurrency market through the creation of KODAKOne, that when developed, would seamlessly register, manage and monetise creative assets for the photographic community. It would be used to underpin the assured buying and selling of rights cleared and protected digital assets while ensuring transparency. Figure 1 presents the price, daily percentage volatility 
and a measure of news sentiment for Kodak (as measured by Google Trends data). It is immediately evident that the announcement had a significant and sharp impact on price volatility (which peaked at over $60 \%$ per day). This finding is in line with the findings of Cooper et al. [2001] who documented a mean rise of $70 \%$ for companies rebranding to include .com in their name in the internet bubble period. This paper is, to date, the first to examine similar effects on blockchain related public company announcements

Kodak is a company that suffered through the adoption of digital imaging technology such as digital SLRs, camera-phones, flash memory and the use of cloud-based platforms for image storage. The imaging industry has also seen sustained attacks on intellectual property rights, most especially images. The non-payment for those image rights to those who create such property has been a challenge to professional photographers and news agencies. Theoretically, KODAKOne provides a blockchain-based licence for each image, which, through the use of web-crawling software, can then be investigated for copyright violations. In theory, payments can be made to the rightful owners of the intellectual property in KODAKCoins. The inherent dangers with such as plan was the potential development of a pricing bubble in Kodak shares as the market struggles to ascertain a fair value for the planned cryptocurrency strategy. However, cryptocurrencies are highly risky products. Cheah and Fry [2015] found that cryptocurrencies are prone to speculative bubbles, with the volatility of the products also investigated by Corbet et al. [2017], Fry and Cheah [2016], Katsiampa [2017] and Pieters and Vivanco [2017]. If mis-priced, this plan could jeopardise Kodak's 6,100 employees should such a pricing bubble burst and drag down the share price.

\section{Data}

We collect data for Kodak and DJIA from Bloomberg and for Bitcoin from CryptoCompare.com. Data were collected on a $5 \mathrm{~m}$ frequency basis with 4,820 observations between 22 November 2017 and 21 February 2018. This time period was selected to best represent market behaviour both before and after the first announcement of KODAKCoin on 9 January 2018. In Figure 2 we see the evolution of these assets. We define returns as the daily $\log$ changes and volatility as the five days standard deviation. Table 1 presents descriptive statistics and correlation matrices for each of the variables.

\section{Empirical approach and results}

We use a standard GARCH $(1,1)$ methodology of Bollerslev [1986] and extract dynamic conditional correlations (of Engle [2002]

The substantial volatility of Bitcoin is exhibited through a five-minute maximum price movement of $+16.8 \%$ and minimum of $-24.6 \%$, while DJIA remains far more subdued. Kodak's price behaviour in the period after the announcement of KODAKCoin presents evidence of a significant behavioural shift. Both the mean and standard deviation of short-term 
returns increase substantially, while the maximum and minmimum values bear similarity with Bitcoin rather than the broad stock market index.

In Table 2 we observe the results of the $\operatorname{GARCH}(1,1)$ estimation. Kodak returns present a significant, but weak $(+0.0714)$ relationship with Bitcoin returns and a very strong significant relationship with DJIA returns $(+0.6811)$. The GARCH specification remains stable as the sum of the coefficients $\alpha_{1}$ and $\beta$ is than unity throughout all specifications. $D_{t}$ is estimated to be +1.128 , indicating a very strong increase in the volatility of Kodak returns in the period after the announcement of KODAKCoin. This presents evidence of a substantial and sustained market response after the association of the Kodak brand with cryptocurrency products.

Investigating both periods separately offers interesting results, with particular emphasis on the relationships between the investigated markets. In the period prior to the KODAKCoin announcement, Kodak shared a very strong relationship as measured by $d j_{t}$ in the mean equation $(+1.1488)$ and a very weak relationship with Bitcoin as measured by $b_{t}$ $(+0.0226)$.

In the period after 9 January 2018 this relationship presents evidence of substantial change as there is a decline in the relationship with DJIA $(+0.8559)$ and a large increase in the relationship between Kodak and Bitcoin $(+0.3731)$. This presents strong evidence that, at a five-minute level, Kodak returns have become strongly related with Bitcoin returns. There is further evidence of a diminished relationship between Kodak and the exchange on which it trades.

To test the robustness of our selected methodology, we analyse the dynamic conditional correlations through the DCC-GARCH methodology with results in Table 3. We again find evidence of sustained increases in the volatility of Bitcoin, with a strong increased relationship between Kodak and Bitcoin returns and a declining relationship between Kodak and DJIA returns. This finding is echoed through an examination of the plotted dynamic correlations in Figure 3.

A plausible explanation as to why the correlations increased in the period after the announcement of KODAKCoin, could be a consequence of the market exuberance attributed to cryptocurrencies. There is strong evidence in our presented results to suggest that Kodak shares, although strongly aligned with stock returns, have, through the simplistic announcement of an unproven cryptocurrency opportunity, absorbed some of the high-volatility and potential bubble-like characteristics that have been identified in Bitcoin (Corbet et al. [2017], Fry and Cheah [2016]). Should a bubble burst in cryptocurrencies markets, announcements such as KODAKCoin present a direct channel in which speculative contagion and detrimental effects can flow from the cryptocurrency markets to equity markets.

\section{Concluding and suggestions for further work}

Our results indicate a substantial and sustained increase in return volatility in the period

after the announcement of Kodak's intention to create a cryptocurrency. Further, there is 
strong evidence that Kodak returns became substantially more correlated with the high-risk, speculative asset class of cryptocurrencies. Without considering the long-run feasibility of the proposed plans of KODAKCoin, our results point towards the existence of a new form of asymmetric information as share value is found to increase dramatically through the simple announcement of any plan relating to a cryptocurrency based on blockchain technology. Such announcements can potentially take advantage of the euphoric and speculative investment motives that have been inflating what some consider to be a significant bubble in cryptocurrency markets. Announcements without strong supporting evidence can present an channel through which speculative contagion can flow from cryptocurrency markets to equity markets. The definition provided by the US Securities and Exchange Commission for a "pump-and-dump" comes to mind ${ }^{1}$ with respect to the performance of the Kodak stock upon the announcement of KodakCoin.

A potential avenue for future research is to examine whether similar patterns can be observed where the equity performance of other traditionally non-cryptocurrency-related companies following an announcement to announcing to enter the cryptocurrency market. This could be supported by further legal and regulatory analysis of such actions.

\section{Bibliography}

Blau, B. M. (2017). Price dynamics and speculative trading in bitcoin. Research in International Business and Finance 41, 493-499.

Bollerslev, T. (1986). Generalized autoregressive conditional heteroskedasticity. Journal of econometrics 31(3), 307-327.

Cheah, E.-T. and J. Fry (2015). Speculative bubbles in bitcoin markets? an empirical investigation into the fundamental value of bitcoin. Economics Letters 130, 32-36.

Cooper, M., O. Dimitrov, and P. Rau (2001). A rose.com by any other name. Journal of Finance 56(6), 2371-2388. cited By 173.

\footnotetext{
'Pump-and-dump' schemes involve the touting of a company's stock (typically small, so-called 'microcap' companies) through false and misleading statements to the marketplace. These false claims could be made on social media such as Facebook and Twitter, as well as on bulletin boards and chat rooms. Pump-and-dump schemes often occur on the Internet where it is common to see messages posted that urge readers to buy a stock quickly or to sell before the price goes down, or a telemarketer will call using the same sort of pitch. Often the promoters will claim to have 'inside' information about an impending development or to use an 'infallible' combination of economic and stock market data to pick stocks. In reality, they may be company insiders or paid promoters who stand to gain by selling their shares after the stock price is 'pumped' up by the buying frenzy they create. Once these fraudsters 'dump' their shares and stop hyping the stock, the price typically falls, and investors lose their money. [US Securities and Exchange Commission, 2018] https://www.sec.gov/fast-answers/answerspumpdumphtm.html
} 
Corbet, S., B. Lucey, and L. Yarovya (2017). Datestamping the bitcoin and ethereum bubbles. Finance Research Letters, forthcoming..

Corbet, S., A. Meegan, C. Larkin, B. Lucey, and L. Yarovaya (2017). Exploring the dynamic relationships between cryptocurrencies and other financial assets. Available at SSRN https://ssrn.com/abstract=3070288.

Corbet, S., A. Meegan, C. Larkin, B. Lucey, and L. Yarovya (2018). Exploring the dynamic relationships between cryptocurrencies and other financial assets. Economics Letters 165, $28-34$.

Dwyer, G. P. (2015). The economics of bitcoin and similar private digital currencies. Journal of Financial Stability 17, 81-91.

Engle, R. (2002). Dynamic conditional correlation: A simple class of multivariate generalized autoregressive conditional heteroskedasticity models. Journal of Business $\&$ Economic Statistics 20(3), 339-350.

Fry, J. and E.-T. Cheah (2016). Negative bubbles and shocks in cryptocurrency markets. International Review of Financial Analysis 47, 343-352.

Katsiampa, P. (2017). Volatility estimation for bitcoin: A comparison of garch models. Economics Letters 158, 3-6.

Pieters, G. and S. Vivanco (2017). Financial regulations and price inconsistencies across bitcoin markets. Information Economics and Policy 39, 1-14.

Urquhart, A. (2016). The inefficiency of bitcoin. Economics Letters 148, 80-82.

US Securities and Exchange Commission (2018). "pump-and-dumps" and market manipulations. 
Figure 1: Bitcoin share price, daily volatility and online information searches (Nov 2017 through Feb 2018)
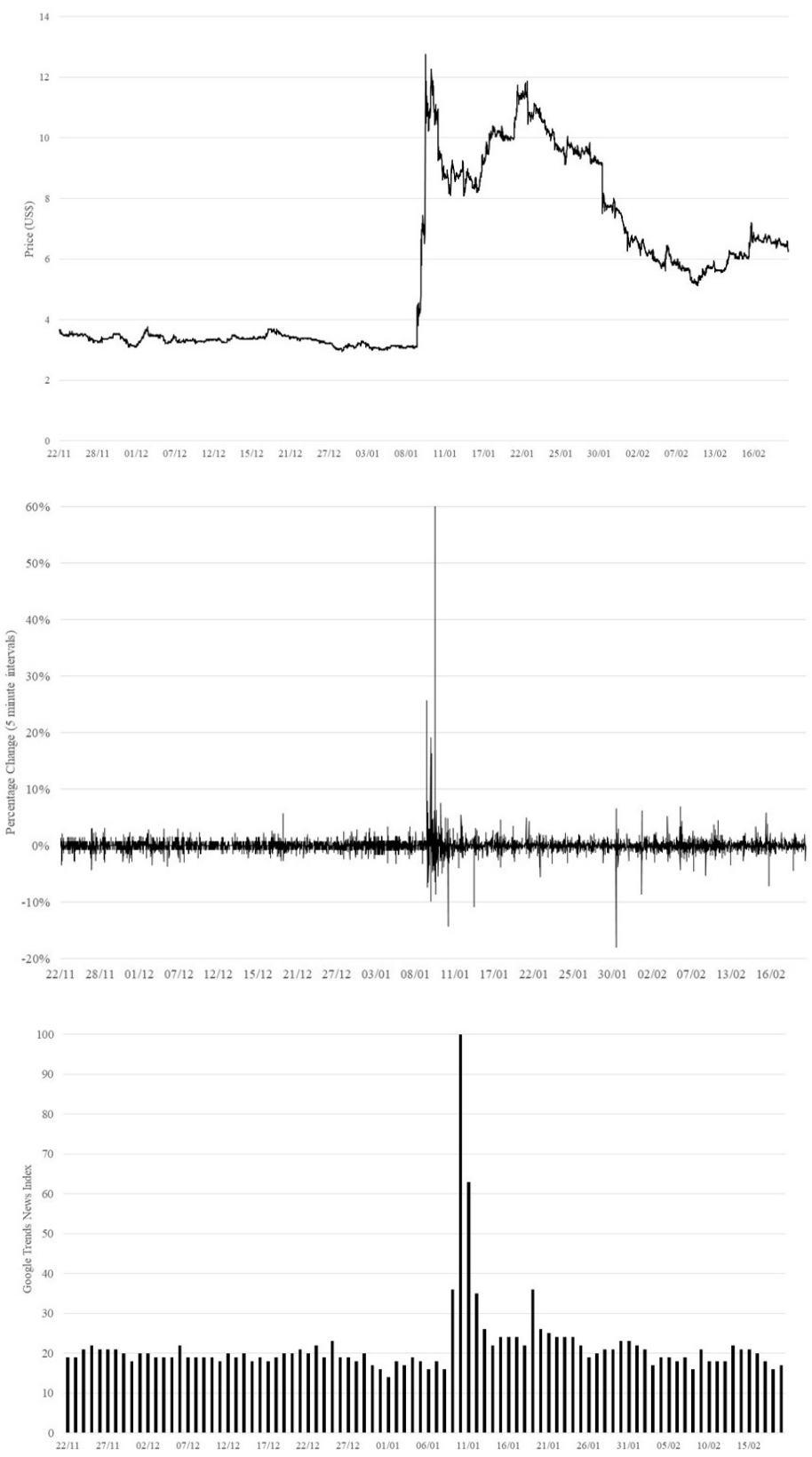

Note: The above data covers the period between 22 November 2017 and 21 February 2018. The above figure represents the the five-minutely time series of Kodak shares. The middle figure represents the five-minutely time series of volatility as measured by the percentage change. The lower figure represents the daily indexed search level for the terms 'Kodak' and 'cryptocurrency' as measured by data obtained from Google Trends. 
Figure 2: Bitcoin share price and Dow Jones Industrial Average (Nov 2017 through Feb 2018)

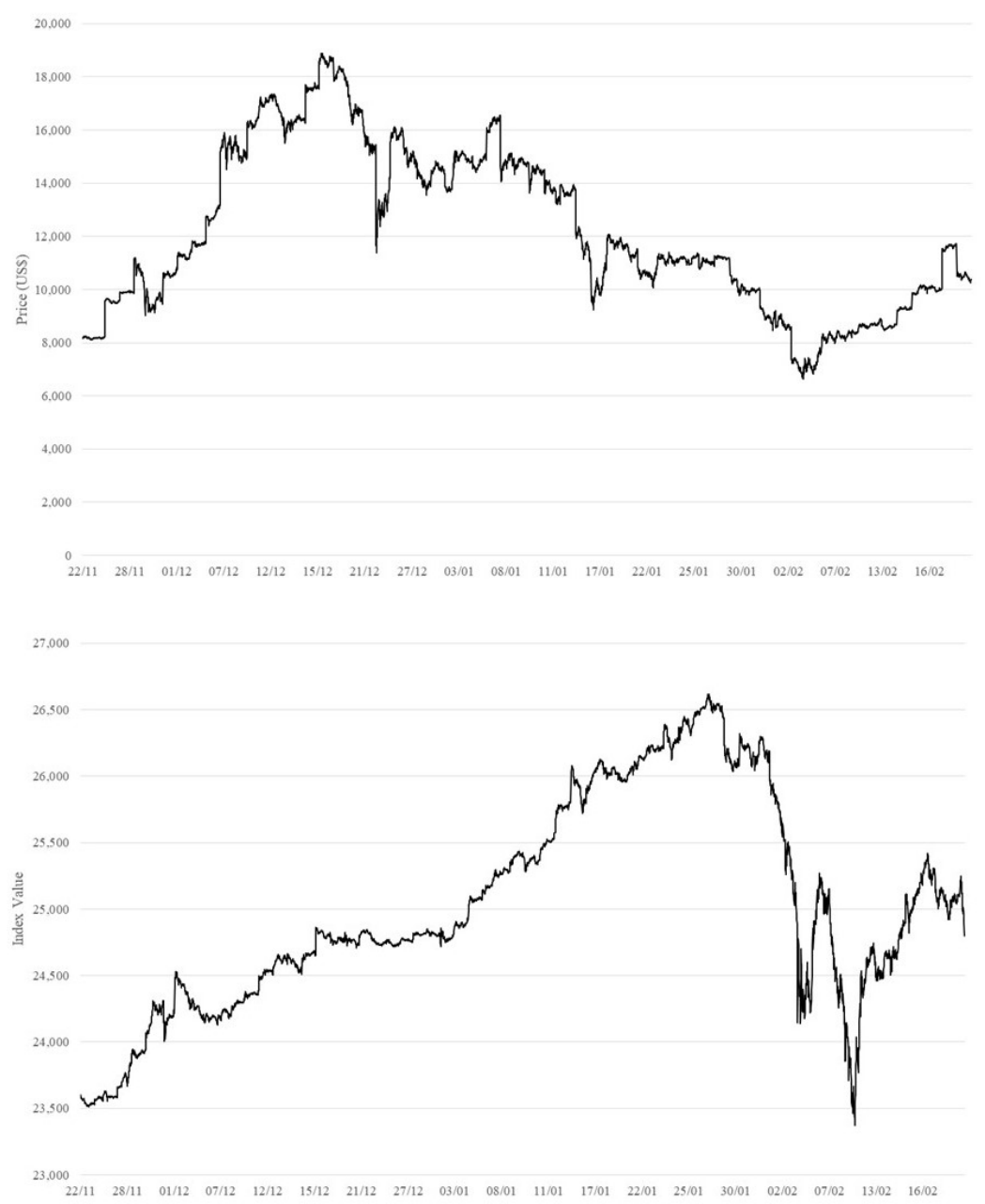

Note: The above data covers the period between 22 November 2017 and 21 February 2018. The above figure represents the five-minutely time series of the price of Bitcoin as measured in US dollars. The lower figure represents five-minutely time series of the Dow Jones Industrial Average. Both are used as independent variables in the selected DCC-GARCH methodology. 
Figure 3: Dynamic conditional correlations of Kodak, Bitcoin and DJIA returns.

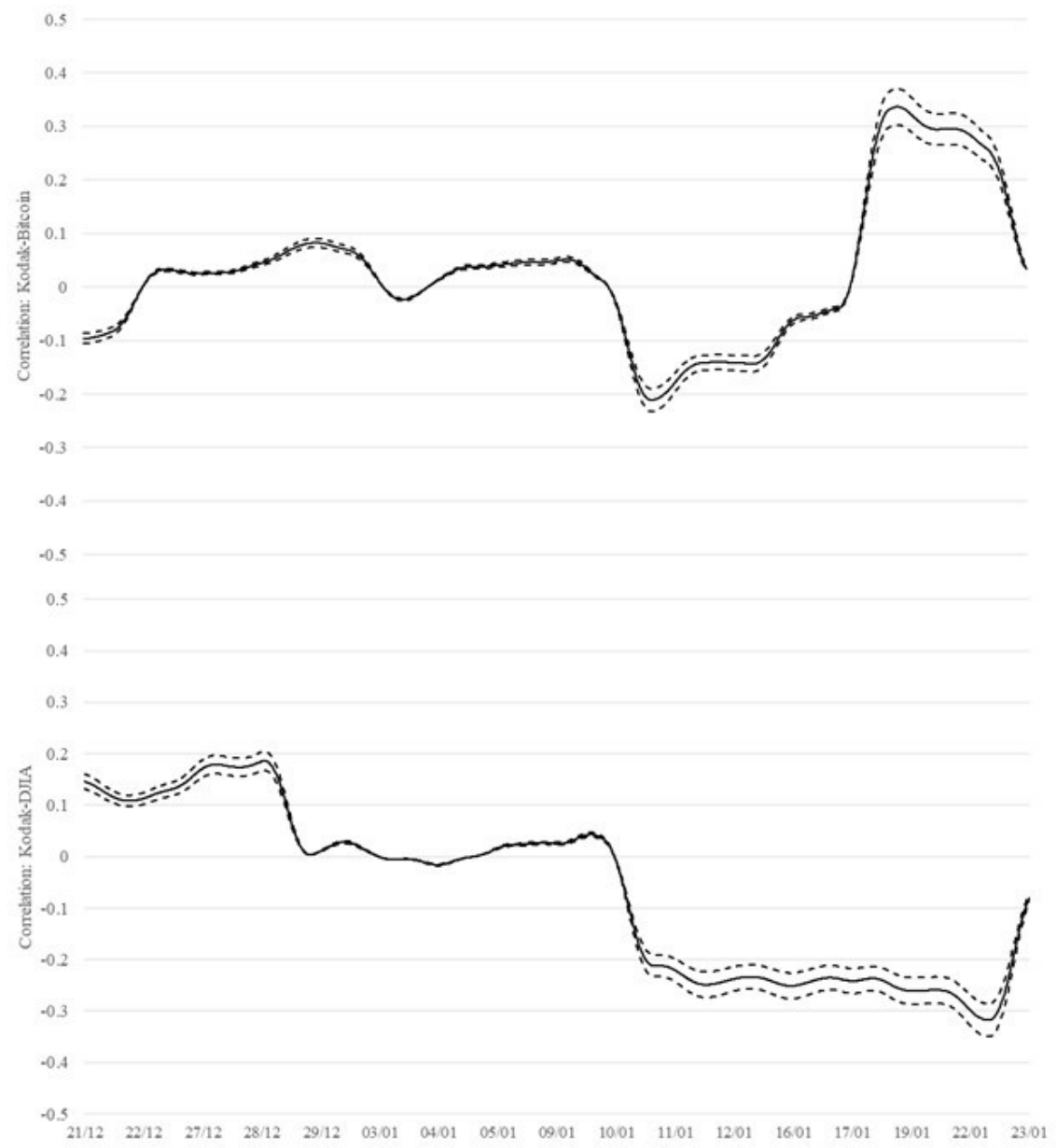

Note: The above data covers the period between 22 November 2017 and 21 February 2018. Dotted lines represent the $90 \%$ confidence intervals. The above figure represents the dynamic conditional correlation between Kodak and Bitcoin while the lower figure represents the dynamic conditional correlation between Kodak and DJIA. 
Table 1: Descriptive statistics and correlations between Kodak, Bitcoin and DJIA

\begin{tabular}{|c|c|c|c|}
\hline \multicolumn{4}{|c|}{ Total Period Investigated } \\
\hline Panel A: Correlations & Kodak & DJIA & Bitcoin \\
\hline Kodak & 1.0000 & & \\
\hline DJIA & 0.0273 & 1.0000 & \\
\hline Bitcoin & 0.0208 & 0.0204 & 1.0000 \\
\hline \multicolumn{4}{|c|}{ Panel B: Descr. Statistics } \\
\hline Observations & 4,819 & 4,819 & 4,819 \\
\hline Mean & 0.0002 & 0.0001 & 0.0001 \\
\hline Standard Deviation & 0.0154 & 0.0011 & 0.0102 \\
\hline Minimum & -0.1803 & -0.0199 & -0.2457 \\
\hline Maximum & 0.6228 & 0.0137 & 0.1682 \\
\hline \multicolumn{4}{|c|}{ Before announcement of KODAKCoin } \\
\hline Panel A: Correlations & Kodak & DJIA & Bitcoin \\
\hline Kodak & 1.0000 & & \\
\hline DJIA & -0.0218 & 1.0000 & \\
\hline Bitcoin & -0.058 & 0.0958 & 1.0000 \\
\hline \multicolumn{4}{|c|}{ Panel B: Descr. Statistics } \\
\hline Observations & 2,340 & 2,340 & 2,340 \\
\hline Mean & -0.0001 & 0.0001 & 0.0002 \\
\hline Standard Deviation & 0.0084 & 0.0005 & 0.0112 \\
\hline Minimum & -0.0435 & -0.0038 & -0.2457 \\
\hline Maximum & 0.0571 & 0.0085 & 0.1682 \\
\hline \multicolumn{4}{|c|}{ After announcement of KODAKCoin } \\
\hline Panel A: Correlations & Kodak & DJIA & Bitcoin \\
\hline Kodak & 1.0000 & & \\
\hline DJIA & 0.0683 & 1.0000 & \\
\hline Bitcoin & 0.1666 & -0.0111 & 1.0000 \\
\hline \multicolumn{4}{|c|}{ Panel B: Descr. Statistics } \\
\hline Observations & 2,480 & 2,480 & 2,480 \\
\hline Mean & 0.0005 & -0.0001 & -0.0001 \\
\hline Standard Deviation & 0.0199 & -0.0014 & 0.0091 \\
\hline Minimum & -0.1803 & -0.0199 & -0.1395 \\
\hline Maximum & 0.6228 & 0.0137 & 0.1463 \\
\hline
\end{tabular}

Note: The periods of investigation before and after the announcement of KODAKCoin are separated on 9 January 2018. 
Table 2: Estimation results of $\operatorname{GARCH}(1,1)$ methodologies

\begin{tabular}{|c|c|c|c|}
\hline & $\begin{array}{l}\text { Model 1: } \\
\text { Total Period }\end{array}$ & $\begin{array}{l}\text { Model 2: } \\
\text { Before KO- } \\
\text { DAKCoin }\end{array}$ & $\begin{array}{l}\text { Model 3: } \\
\text { After KO- } \\
\text { DAKCoin }\end{array}$ \\
\hline \multicolumn{4}{|c|}{ Panel A: Conditional Mean } \\
\hline$\overline{\overline{\text { Constant }}}$ & $\begin{array}{l}0.0002^{*} \\
(0.0001)\end{array}$ & $\begin{array}{l}0.0004^{*} \\
(0.0002)\end{array}$ & $\begin{array}{l}-0.0016^{* * *} \\
(0.0003)\end{array}$ \\
\hline$k_{t-1}$ & $\begin{array}{l}-0.3262^{* * *} \\
(0.0178)\end{array}$ & $\begin{array}{l}-0.4508^{* * *} \\
(0.0223)\end{array}$ & $\begin{array}{l}-0.0774 * * * \\
(0.0220)\end{array}$ \\
\hline$k_{t-2}$ & $\begin{array}{l}-0.1515^{* * *} \\
(0.0201)\end{array}$ & $\begin{array}{l}-0.221 * * * \\
(0.0250)\end{array}$ & $\begin{array}{l}-0.1149 * * * \\
(0.0239)\end{array}$ \\
\hline$k_{t-3}$ & $\begin{array}{l}-0.1064 * * * \\
(0.0193)\end{array}$ & $\begin{array}{l}-0.1494 * * * \\
(0.0249)\end{array}$ & $\begin{array}{l}-0.1090^{* * *} \\
(0.0172)\end{array}$ \\
\hline$k_{t-4}$ & $\begin{array}{l}-0.0403^{* *} \\
(0.0157)\end{array}$ & $\begin{array}{l}-0.1105 * * * \\
(0.0232)\end{array}$ & $\begin{array}{l}-0.0029 \\
(0.0163)\end{array}$ \\
\hline$b_{t}$ & $\begin{array}{l}0.0714^{* * * *} \\
(0.0073)\end{array}$ & $\begin{array}{l}0.0226^{* *} \\
(0.0100)\end{array}$ & $\begin{array}{l}0.3731^{* * *} \\
(0.0104)\end{array}$ \\
\hline$b_{t-1}$ & $\begin{array}{l}0.0061 * \\
(0.0135)\end{array}$ & $\begin{array}{l}-0.0032 \\
(0.0130)\end{array}$ & $\begin{array}{l}-0.0947 * * * \\
(0.0175)\end{array}$ \\
\hline$b_{t-2}$ & $\begin{array}{l}0.0113^{*} \\
(0.0128)\end{array}$ & $\begin{array}{l}0.0069 \\
(0.0152)\end{array}$ & $\begin{array}{l}0.1299^{* * *} \\
(0.0209)\end{array}$ \\
\hline$b_{t-3}$ & $\begin{array}{l}-0.0433^{* * * *} \\
(0.0141)\end{array}$ & $\begin{array}{l}-0.0365^{* * *} \\
(0.0140)\end{array}$ & $\begin{array}{l}-0.0284 \\
(0.0186)\end{array}$ \\
\hline$b_{t-4}$ & $\begin{array}{l}0.0355^{* * *} \\
(0.0110)\end{array}$ & $\begin{array}{l}0.0134 \\
(0.0148)\end{array}$ & $\begin{array}{l}-0.0129 \\
(0.0206)\end{array}$ \\
\hline$d j_{t}$ & $\begin{array}{l}0.6811^{* * * *} \\
(0.0704)\end{array}$ & $\begin{array}{l}1.1488^{* * * *} \\
(0.2285)\end{array}$ & $\begin{array}{l}0.8559 * * * \\
(0.1062)\end{array}$ \\
\hline$d j_{t-1}$ & $\begin{array}{l}0.2492^{*} \\
(0.1579)\end{array}$ & $\begin{array}{l}0.8087^{* * * *} \\
(0.2365)\end{array}$ & $\begin{array}{l}0.0696 \\
(0.1574)\end{array}$ \\
\hline$d j_{t-2}$ & $\begin{array}{l}0.3216^{*} \\
(0.1727)\end{array}$ & $\begin{array}{l}1.1397^{* * *} * \\
(0.2592)\end{array}$ & $\begin{array}{l}0.3691 * * \\
(0.1626)\end{array}$ \\
\hline$d j_{t-3}$ & $\begin{array}{l}0.2733^{*} \\
(0.1683)\end{array}$ & $\begin{array}{l}0.1154 \\
(0.2971)\end{array}$ & $\begin{array}{l}0.3485^{* * * *} \\
(0.1291)\end{array}$ \\
\hline$d j_{t-4}$ & $\begin{array}{l}0.0900 \\
(0.1624)\end{array}$ & $\begin{array}{l}0.2088 \\
(0.2677)\end{array}$ & $\begin{array}{l}-0.2709^{*} \\
(0.1182)\end{array}$ \\
\hline Newst & $\begin{array}{l}0.0450 * * * \\
(0.0016)\end{array}$ & $\begin{array}{l}-0.0232^{* * *} \\
(0.0105)\end{array}$ & $\begin{array}{l}0.0623^{* * * *} \\
(0.0032)\end{array}$ \\
\hline Mon $_{t}$ & $\begin{array}{l}0.0006 * * * \\
(0.0003)\end{array}$ & $\begin{array}{l}0.0005 \\
(0.0005)\end{array}$ & $\begin{array}{l}0.0020 * * * \\
(0.0005)\end{array}$ \\
\hline Tuest & $\begin{array}{l}-0.0002^{*} \\
(0.0003)\end{array}$ & $\begin{array}{l}0.0003 \\
(0.0004)\end{array}$ & $\begin{array}{l}0.0017 * * * \\
(0.0004)\end{array}$ \\
\hline$W e d s_{t}$ & $\begin{array}{l}-0.0001 \\
(0.0003)\end{array}$ & $\begin{array}{l}0.0001 \\
(0.0004)\end{array}$ & $\begin{array}{l}0.0004 \\
(0.0005)\end{array}$ \\
\hline Thurs $_{t}$ & $\begin{array}{l}-0.0001 \\
(0.0003)\end{array}$ & $\begin{array}{l}0.0003 \\
(0.0004)\end{array}$ & $\begin{array}{l}0.0002 \\
(0.0004)\end{array}$ \\
\hline \multicolumn{4}{|c|}{ Panel B: Conditional variance } \\
\hline$\gamma$ & $\begin{array}{l}0.1171^{* * *} \\
(0.0045)\end{array}$ & $\begin{array}{l}0.0001^{* * *} \\
(0.0000)\end{array}$ & $\begin{array}{l}0.0001^{* * *} \\
(0.0000)\end{array}$ \\
\hline$\alpha_{1}$ & $\begin{array}{l}0.2487^{* * *} \\
(0.0084)\end{array}$ & $\begin{array}{l}0.1336^{* * *} \\
(0.0132)\end{array}$ & $\begin{array}{l}0.1086^{* * *} \\
(0.0045)\end{array}$ \\
\hline$\beta_{1}$ & $\begin{array}{l}0.6691 * * * \\
(0.0106)\end{array}$ & $\begin{array}{l}0.7924^{* * *} \\
(0.0184)\end{array}$ & $\begin{array}{l}0.8449^{* * *} \\
(0.0177)\end{array}$ \\
\hline$D_{t}$ & $\begin{array}{l}1.1280^{* * *} * \\
(0.0451)\end{array}$ & & \\
\hline Observations & 4,820 & 2,333 & 2,480 \\
\hline Prob $>C h i^{2}$ & 0.0000 & 0.0000 & 0.0000 \\
\hline Log likelihood & $15,442.57$ & $8,127.80$ & $7,476.65$ \\
\hline
\end{tabular}

Note: $k_{t}, b_{t}$ and $d j_{t}$ denote the daily returns for Kodak, Bitcoin and DJIA respectively. $D_{t}$ is a dummy variable that equals one for the period of time after the 9 January 2018 at the time of the announcement of KODAKCoin, and zero otherwise. As a robustness check, Model two and Model three denote two individual GARCH $(1,1)$ methodologies that examine the relationships between the selected methodology without the inclusion of $D_{t} .{ }^{* * *},{ }^{* *}$ and ${ }^{*}$ denote significance at the $1 \%, 5 \%$ and $10 \%$ levels respectively. 
Table 3: Estimation results of DCC-GARCH methodologies

\begin{tabular}{|c|c|c|c|c|c|}
\hline & \multicolumn{2}{|c|}{$\begin{array}{l}\text { Model 1: } \\
\text { Kodak and DJIA }\end{array}$} & & \multicolumn{2}{|c|}{ Model 2} \\
\hline & $k_{t}$ & $d j_{t}$ & & $k_{t}$ & $b_{t}$ \\
\hline \multicolumn{6}{|c|}{ Panel A: Conditional Mean } \\
\hline Constant & $\begin{array}{l}0.0002^{* *} \\
(0.0001)\end{array}$ & $\begin{array}{l}0.0001^{* * *} \\
(0.0000)\end{array}$ & Constant & $\begin{array}{l}0.0002^{* * *} \\
(0.0001)\end{array}$ & $\begin{array}{l}0.0001 \\
(0.0001)\end{array}$ \\
\hline$k_{t-1}$ & $\begin{array}{l}-0.3401^{* * *} \\
(0.0196)\end{array}$ & $\begin{array}{l}-0.0412^{* *} \\
(0.0196)\end{array}$ & $k_{t-1}$ & $\begin{array}{l}-0.3331^{* * *} \\
(0.0171)\end{array}$ & $\begin{array}{l}-0.0284^{*} \\
(0.0161)\end{array}$ \\
\hline$k_{t-2}$ & $\begin{array}{l}-0.1577^{* * *} \\
(0.0194)\end{array}$ & $\begin{array}{l}-0.0429 * * \\
(0.0196)\end{array}$ & $k_{t-2}$ & $\begin{array}{l}-0.1533^{* * *} \\
(0.0191)\end{array}$ & $\begin{array}{l}0.0234 \\
(0.0167)\end{array}$ \\
\hline$k_{t-3}$ & $\begin{array}{l}-0.1021^{* * *} \\
(0.0189)\end{array}$ & $\begin{array}{l}0.0185 \\
(0.0199)\end{array}$ & $k_{t-3}$ & $\begin{array}{l}-0.0956^{* * *} \\
(0.0188)\end{array}$ & $\begin{array}{l}0.0037 \\
(0.0132)\end{array}$ \\
\hline$k_{t-4}$ & $\begin{array}{l}-0.0294^{*} \\
(0.0165)\end{array}$ & $\begin{array}{l}-0.0386^{* *} \\
(0.0191)\end{array}$ & $k_{t-4}$ & $\begin{array}{l}-0.0226 \\
(0.0149)\end{array}$ & $\begin{array}{l}-0.0237^{*} \\
(0.0145)\end{array}$ \\
\hline$h_{k_{t}}$ & $\begin{array}{l}0.2557^{* * *} \\
(0.1365)\end{array}$ & $\begin{array}{l}0.0004^{* * *} \\
(0.0001)\end{array}$ & $h_{k_{t}}$ & $\begin{array}{l}0.1827^{* * * *} \\
(0.0051)\end{array}$ & $\begin{array}{l}-0.0284^{* * *} \\
(0.0016)\end{array}$ \\
\hline$h_{d j_{t}}$ & $\begin{array}{l}-0.0001^{* * *} \\
(0.0000)\end{array}$ & $\begin{array}{l}0.0205^{* * *} \\
(0.0007)\end{array}$ & $h_{b_{t}}$ & $\begin{array}{l}0.0064^{* * *} \\
(0.0013)\end{array}$ & $\begin{array}{l}0.8062 * * * \\
(0.0042)\end{array}$ \\
\hline $\mathrm{D}$ & $\begin{array}{l}1.1945^{* * *} \\
(0.0774)\end{array}$ & $\begin{array}{l}0.2991 * * * \\
(0.0225)\end{array}$ & $\mathrm{D}$ & $\begin{array}{l}1.1846^{* * *} \\
(0.0401)\end{array}$ & $\begin{array}{l}-0.4101^{* * *} \\
(0.0068)\end{array}$ \\
\hline \multicolumn{6}{|c|}{ Panel B: Conditional variance } \\
\hline $\bar{\gamma}$ & $\begin{array}{l}0.1177^{* * *} \\
(0.0013)\end{array}$ & $\begin{array}{l}0.1779^{* * *} \\
(0.0009)\end{array}$ & & $\begin{array}{l}0.1185^{* * *} \\
(0.0040)\end{array}$ & $\begin{array}{l}0.122^{* * *} \\
(0.0068)\end{array}$ \\
\hline$\alpha_{1}$ & $\begin{array}{l}0.2571^{* * *} \\
(0.0182)\end{array}$ & $\begin{array}{l}0.1676^{* * *} \\
(0.0115)\end{array}$ & & $\begin{array}{l}0.2429 * * * \\
(0.0069)\end{array}$ & $\begin{array}{l}0.0019 * * * \\
(0.0005)\end{array}$ \\
\hline$\beta_{1}$ & $\begin{array}{l}0.6787 * * * \\
(0.0225)\end{array}$ & $\begin{array}{l}0.8153^{* * *} \\
(0.0094)\end{array}$ & & $\begin{array}{l}0.6788^{* * *} \\
(0.0089)\end{array}$ & $\begin{array}{l}0.9578^{* * *} \\
(0.0073)\end{array}$ \\
\hline $\mathrm{a}$ & $\begin{array}{l}0.0361^{* *} \\
(0.0110)\end{array}$ & & & $\begin{array}{l}0.0594 * * * \\
(0.0292)\end{array}$ & \\
\hline $\mathrm{b}$ & $\begin{array}{l}0.8311^{* * *} \\
(0.0405)\end{array}$ & & & $\begin{array}{l}0.8542^{* * *} \\
(0.0381)\end{array}$ & \\
\hline
\end{tabular}

Note: ${ }^{* * *},{ }^{* *}$ and ${ }^{*}$ denote significance at the $1 \%, 5 \%$ and $10 \%$ levels respectively. 